\title{
Comprometimento de mãos e punhos no diabetes tipo 2 - relato de caso
}

\section{Involvement of hands and wrists in type $\mathbf{2}$ diabetes - case report}

Rafael Esdras Brito Garganta da Silvaํ. Sandra Lúcia Euzébio Ribeiroํ. Bruno Meireles de Brito Souza ${ }^{1}$. Carla Caroline Oliveira de Souza ${ }^{1}$. Rebeca Patrícia Quereza e Silva Faria ${ }^{1}$. Raquel Patrícia Quereza e Silva Faria $^{1}$.

1 Universidade Federal do Amazonas (UFAM), Manaus, Amazonas, Brasil.

\section{RESUMO}

O diabetes mellitus tipo 2 (DM2) é uma doença crônica de alta prevalência no mundo, a qual é causadora de importante morbimortalidade devido às suas complicações sistêmicas. Dentre elas, inclui-se as manifestações musculoesqueléticas caracterizadas pelo comprometimento ósseo e de tecido mole periarticular. Relata-se o caso de paciente do sexo feminino de 48 anos com DM2 e hipertensa há 12 anos, a mesma foi encaminhada por meio de um projeto de pesquisa ao serviço de reumatologia. No atendimento médico, relata um quadro de dor crônica com início em 2015, principalmente da mão esquerda com parestesia em punho. Além disso, relata que o dedo anelar da mesma mão se torna rígido necessitando deslocá-lo para voltar a sua posição normal. Pelos achados de exame físico e de imagem constatou-se um diagnóstico de tendinite de Quervain, dedo em gatilho e síndrome do túnel do carpo. Espera-se com esse relato conscientizar outros profissionais da real importância do tema. Torna-se imprescindível a exploração de queixas musculoesqueléticas objetivando um diagnóstico precoce, evitando um comprometimento na qualidade de vida de pacientes semelhantes a esse.

Palavras-chave: Diabetes mellitus. Síndrome do túnel do carpo. Dedo em gatilho. Tendinopatia.

\section{ABSTRACT}

Type 2 diabetes mellitus (DM2) is a chronic disease of high prevalence in the world, an important cause of morbidity and mortality due to its systemic complications. Among them, the musculoskeletal manifestations characterized by bone and periarticular molar involvement are included. Case report of a 48-year-old female patient with T2DM and hypertension for 12 years, she was referred to the research project at the rheumatology department. In the medical care, she reported a pain chart beginning in 2015 , mainly in the left hand with paresthesia in the wrist. Also, reports that the ring finger of the same hand becomes rigid, being necessary to move it, turning back to its normal position. From the findings of physical examination and imaging is a diagnosis of tendinitis of Quervain, trigger finger and carpal tunnel syndrome. It is hoped the report will make other professionals aware of the real importance of the theme. It is essential for the exploration of musculoskeletal complaints aiming at an early diagnosis, avoiding a compromise in the quality of life of the patient with this aspect.

Keywords: Diabetes mellitus. Carpal tunnel syndrome. Trigger finger disorder. Tendinopapthy.

Autor correspondente: Rafael Esdras Brito Garganta da Silva, Rua das Águias, Vila Militar Ajuricaba, São Lázaro, Manaus, Amazonas, Brasil. CEP: 69073-140. Telefone: +5592 98263-0701. E-mail: resdrasbg@gmail.com

Conflito de interesses: Não há qualquer conflito de interesses por parte de qualquer um dos autores.

Recebido em: 27 Mar 2019; Revisado em: 27 Ago 2020; Aceito em: 21 Out 2020. 


\section{INTRODUÇÃO}

O diabetes mellitus tipo 2 (DM2) é uma das doenças crônicas não transmissíveis de maior prevalência. Nesses últimos anos, a Federação Internacional de Diabetes (IDF) prevê um total de 629 milhões de pacientes diagnosticados pelo mundo em 2065. Soma-se a isso os impactos negativos pela doença, levando ao aumento da morbimortalidade, incapacidades físicas e perda da qualidade de vida. ${ }^{2}$

Essa série de eventos é resultado das complicações geradas pela hiperglicemia crônica, a qual leva sobretudo a complicações vasculares. Além disso, há outras repercussões clínicas pouco reconhecidas e desvalorizadas no atendimento médico desses pacientes: as complicações musculoesqueléticas. ${ }^{3}$ As mesmas se caracterizam pelo comprometimento tanto articular como de tecido ósseo e de tecidos moles, resultando em incapacidade física e funcional crônica. ${ }^{4}$

Várias classificações foram propostas por autores na tentativa de classificar essas manifestações, a mais recente proposta ${ }^{5}$ é compreendida por três grupos: condições unicamente encontradas no diabetes, como infarto muscular; condições frequentemente encontradas no diabetes, como dedo em gatilho, síndrome do túnel do carpo e capsulite de ombro; condições com fatores de risco compartilhados para síndrome metabólica, incluindo gota e osteoartrite. ${ }^{6}$

\section{RELATO DE CASO}

Paciente do sexo feminino com 48 anos, natural e residente de Manaus, afastada do emprego por invalidez. Faz acompanhamento do diabetes tipo 2 e da hipertensão desde 2007. Por meio do projeto de iniciação científica aprovado pelo Comitê de Ética da Universidade Federal do Amazonas, em 2018 , cujo número do parecer é 2.844 .653 , foi encaminhada ao ambulatório de reumatologia devido às queixas de dores articulares.

No atendimento, relatou-se que em 2015, houve um início de um quadro de dor intensa sobretudo em região palmar da mão esquerda acompanhada de parestesia em punhos e nos dedos (polegar, médio, indicador). Esses sintomas pioravam logo após a realização de movimentos repetitivos, principalmente ao digitar no trabalho, e durante o sono. Nesse mesmo período, a paciente descreve um enrijecimento do dedo anelar da mão esquerda, necessitando flexioná-lo ou estendê-lo passivamente para movê-lo. Nesse mesmo ano, revela que o diabetes estava descompensado, com medidas frequentes de hiperglicemia e idas frequentes à emergência médica.

Ao exame físico, na inspeção, a mão esquerda está levemente hipotrofiada em região tenar, manobra de Phalen positiva e sinal de Tinel positivo. ${ }^{7}$ Ambos os testes foram detectados na mão esquerda e estão reproduzidos nas Figuras 1 e 2. Além disso, identificou-se preensão reduzida na mesma mão.

Na ocasião foram solicitados exames de imagem: ultrassom de punhos direito e esquerdo a partir das hipóteses diagnósticas de síndrome de túnel do carpo e dedo em gatilho. As imagens do exame podem ser visualizadas nas Figuras 3 e 4 . Os principais achados foram: nervo mediano espessado com área de secção transversa de $0,12 \mathrm{~cm}^{2}$, sendo normal até $0,10 \mathrm{~cm}^{2}$; áreas de heterogenicidade no $1^{\circ}$ e $3^{\circ}$ compartimento de extensores. Desse modo, confirmam-se os diagnósticos de: tendinite de Quervain; síndrome do túnel do carpo e dedo em gatilho.

Esses achados de imagem foram precedidos de exames laboratoriais. Na ocasião, os resultados demonstraram um descontrole do diabetes: glicemia de $236 \mathrm{mg} / \mathrm{dL}$ e hemoglobina glicada de 10,3\%. Além disso, constatou-se obesidade grau 1 com IMC de $31 \mathrm{~kg} / \mathrm{m}^{2}$.

Quantoà condição atual, encontra-se em tratamento dasíndrome do túnel do carpo com uso de gabapentina em doses mínimas duas vezes ao dia, órtese para ambas as mãos e realização de sessões de fisioterapia motora e anti-inflamatória. Para a condição do dedo em gatilho, receitou-se nimesulida por 30 dias. A paciente relata melhora do quadro e está respondendo bem ao tratamento atual do diabetes com hemoglobina glicada atual de 7,09\%.

Figura 1. Paciente do projeto de pesquisa executando a manobra de Phalen, a qual consiste na compressão do nervo mediano após a hiperflexão ativa do punho durante 60 segundos.

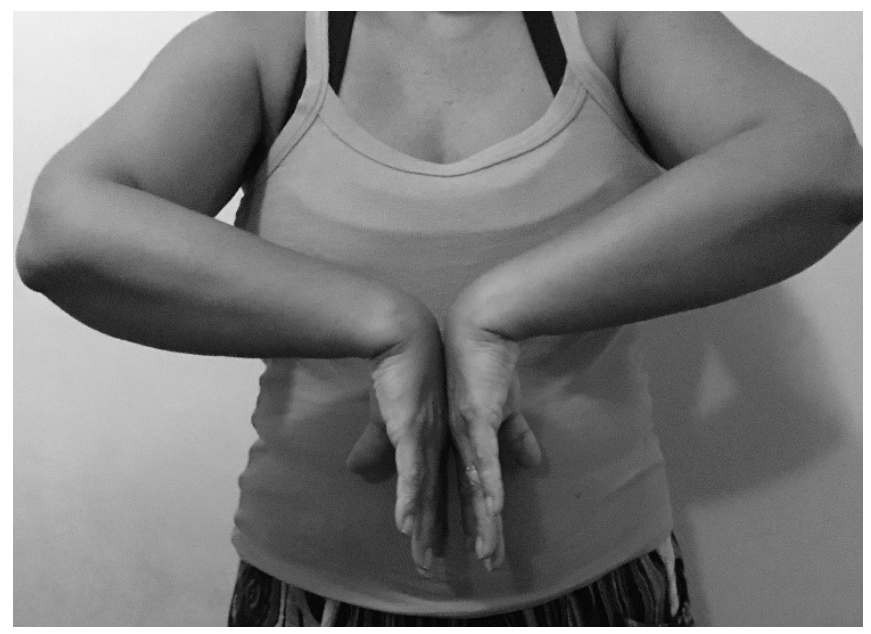

Figura 2. Paciente recebendo percussão no eixo médio do punho que pode gerar desconforto ao haver compressão.

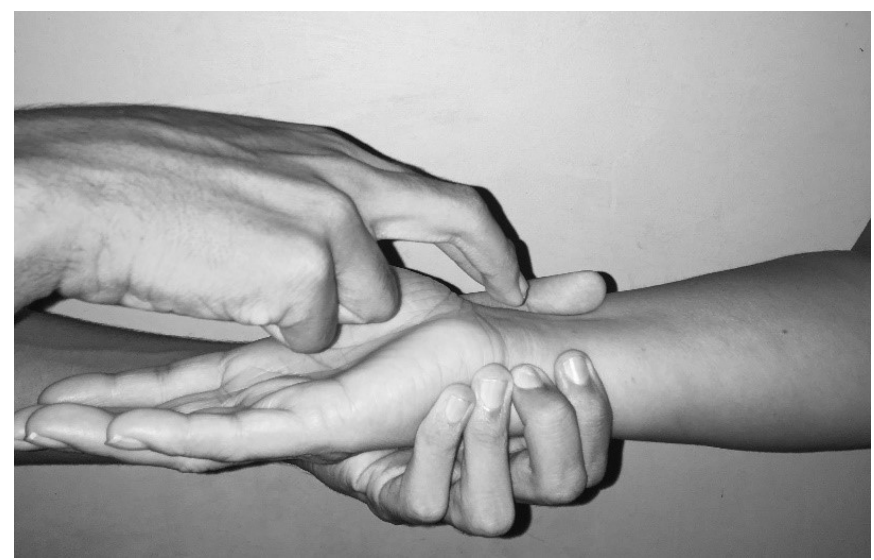


Figura 3. Espessamento do nervo mediano no punho esquerdo da paciente com área de secção transversa de $0,12 \mathrm{~cm}^{2}$ e comprimento de $1,50 \mathrm{~cm}$.

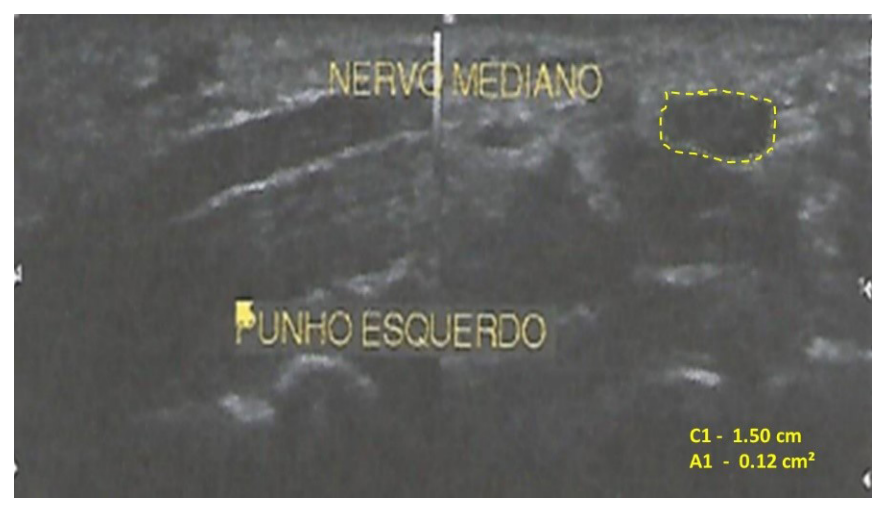

Figura 4. Espessamento do nervo mediano no punho direito da paciente com área transversa de $0,12 \mathrm{~cm}^{2}$ e comprimento de $1,58 \mathrm{~cm}$.

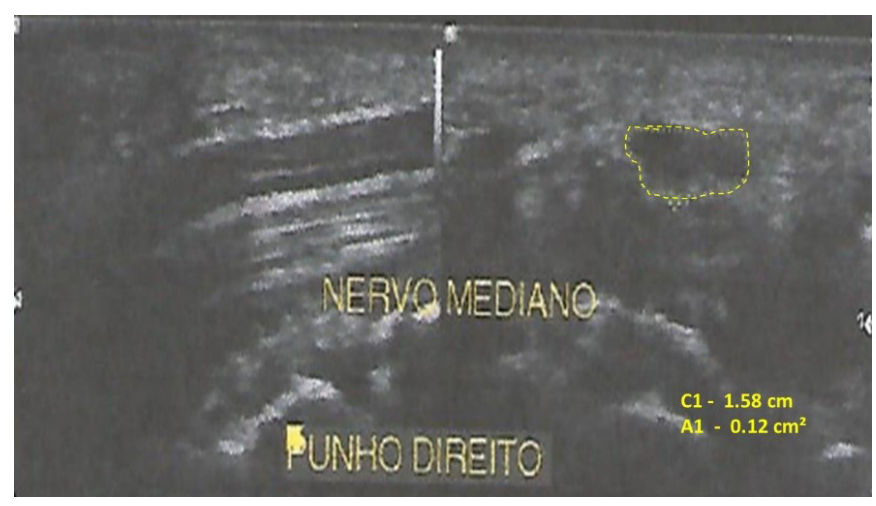

\section{DISCUSSÃO}

Em geral, a etiologia e a fisiopatologia das manifestações musculoesqueléticas não estão bem esclarecidas. Uma das possíveis explicações está no aumento da glicosilação não enzimática do colágeno, resultando em produtos finais de glicação avançada. Adiciona-se a esse processo a elevação dos níveis de espécies reativas de oxigênio que acarreta na liberação de mediadores inflamatórios e moléculas de adesão tecidual. Esse processo é acelerado ao ocorrer níveis persistentemente elevados de glicemia. ${ }^{8}$

Desse modo, a paciente apresentada no caso tem uma clínica muito sugestiva de síndrome do túnel do carpo que se confirmou pelo uso do ultrassom. Tal afecção é considera como importante causa de complicação do diabetes, a prevalência da mesma varia entre $11 \%$ a $25 \%$ com predominância pelo sexo feminino. ${ }^{9}$

Algumas das explicações para isso está nas alterações na bainha mielinizada e nas densidades dos vasos capilares endoneurais do nervo mediano. Outra alteração encontrada envolve um excesso de fibrose não-inflamatória com a formação de feixes irregulares de colágeno, neoangiogênese e aumento dos níveis de fator de crescimento do tecido conjuntivo conhecido como fator de crescimento do tecido conjuntivo (CTFG). ${ }^{10}$

O manejo dessa condição se dá com o uso de talas e analgésicos. ${ }^{10}$ Optou-se pelo uso da gabapentina pelo fato de contribuir no controle da dor neuropática principalmente de indivíduos com diabetes, e a órtese contribui no alívio dos sintomas por conta da flexão de punho durante o sono.

Duas formas de tenossinovites foram identificadas no caso: tendinite de Quervain e dedo em gatilho. Tais condições são marcadas por um processo inflamatório em qualquer região onde os tendões dos músculos extensores e flexores dos dedos atravessam abaixo do retináculo da mão. ${ }^{11}$

A primeira doença afeta o primeiro compartimento extensor dorsal o qual contém os tendões do extensor curto do polegar e abdutor longo do polegar. Normalmente, o quadro clínico é de dor no lado radial do punho, assim como há limitação na extensão e abdução do polegar. ${ }^{12} \mathrm{O}$ tratamento consiste pelo uso de imobilização com tala do polegar, anti-inflamatórios não esteroides (AINEs) e infiltração de corticosteroides. ${ }^{13}$ Para o caso apresentado, optou-se apenas pelo uso de AINEs.

Em relação ao dedo em gatilho, o mesmo se manifestou pela rigidez do dedo anelar da paciente. Estima-se que os pacientes diabéticos são mais susceptíveis de desenvolver esse distúrbio, com uma prevalência de $5 \%$ a $20 \%$ comparado ao risco de $1 \%$ a $2 \%$ na população geral. ${ }^{14}$ A hiperglicemia crônica faz parte da fisiopatologia do quadro, o qual leva ao aumento de ligações cruzadas do colágeno que se acumulam ao redor das bainhas do tendão do músculo flexor dos dedos. ${ }^{15}$

A evolução dessa doença não é favorável aos pacientes com diabetes. Isso porque outras condições como a queiroartropatia e síndrome da mão rígida estão presentes concomitantemente com o dedo em gatilho. ${ }^{16} \mathrm{~A}$ maioria dos casos requerem tratamento cirúrgico com a liberação a céu aberto da polia A1. ${ }^{17}$ Esse tipo de procedimento não se enquadra para a paciente em questão, já que houve boa resposta ao tratamento conservador.

\section{CONCLUSÃO}

As complicações musculoesqueléticas têm participação marcante na evolução do DM2 apesar de haver mecanismos fisiopatológicos pouco elucidados. ${ }^{17} \mathrm{~A}$ partir do relato apresentado, percebe-se que esse tipo de comprometimento é frequentemente um fator contribuinte na morbimortalidade desses pacientes. Para isso, no atendimento médico, é imprescindível avaliação adequada de qualquer queixa de envolvimento periarticular ou muscular a fim de haver um diagnóstico precoce e menor perda da qualidade de vida. 


\section{REFERÊNCIAS}

1. International Diabetes Federation (IDF). IDF Diabetes Atlas. 8. ed. Brussels: International Diabetes Federation; 2017. Belgium: International Diabetes Federation, 2019.

2. Bommer C, Sagalova V, Heesemann E, Manne-Goehler J, Atun R, Davies J, et al. Global economic burden of diabetes in adults: projections from 2015 to 2030. Diabetes care. 2018;41(5):963-70.

3. Bañón S, Isenberg DA. Rheumatological manifestations occurring in patients with diabetes mellitus. Scand J Rheumatol. 2013;42(1):110

4. Attar SM. Musculoskeletal manifestations in diabetic patients at a tertiary center. Libyan J Med. 2012;7:1-7.

5. Lebiedz-Odrobina D, Kay J. Rheumatic manifestation of diabetes mellitus. Rheum Dis Clin North Am. 2010;36(4):681-99.

6. Bhat TA, Dhar SA, Dar Ta, Naikoo MA, Naqqash MA, Bhat A, et al. The musculoskeletal manifestations of type 2 Diabetes Mellitus in a Kashmiri population. Int J Health Sci (Qassim). 2016;10(1):57-68.

7. Almasi-doghaee M, Boostani R, Saeedi M, Ebrahimzadeh S, Moghadam-Ahmadi A, Saeedi-Borujeni MJ. Carpal compression, Phalen's and Tinel's test: which one is more suitable for carpal tunnel syndrome? Iran J Neurol. 2016; 15(3):173-4.

8. Cárdenas-León M, Diaz-Diaz E, Argüelles-Medina R, SánchezCanales P, Diaz-Sanchez V, Larrea F. [Glycation and protein crosslinking in the diabetes and ageing pathogenesis]. Rev Invest Clin. 2009;61(6):505-20. Article in Spanish.

9. Papanas N, Maltezos E. The diabetic hand: a forgotten complication? J Diabetes Complications. 2010;24(3):154-62.
10. Donato G, Galasso O, Valentino P, Conforti F, Zuccala V, Russo E, et al. Pathological findings in subsynovial connective tissue in idiopathic carpal tunnel syndrome. Clin Neuropathol. 2009;28(2):129-35.

11. Durham CO, Vanravenstein K. It's all in the wrist: diagnosis and management of carpal tunnel syndrome. Orthop Nurs. 2017;36(5):323-7.

12. Firestein GS, Budd RC, Gabriel SE, Mcinnes IB, O'dell JR. Kelley's textbook of rheumatology. 9. ed. [place unknown]: Elsevier Saunders; 2017.

13. GoeL R, Abzug JM. de Quervain 's tenosynovitis: a review of the rehabilitative options. Hand (N Y). 2015;10(1):1-5.

14. Abate M, Schiavone C, Salini V, Andia I. Management of limited joint mobility in diabetic patients. Diabetes Metab Syndr Obes. 2013;6:197-207.

15. Goyal A, Tiwari V, Gupta Y. Diabetic hand: a neglected complication of Diabetes Mellitus. Cureus. 2018;10(6):1-2.

16. Kuczmarski AS, Harris AP, Gil JA, Weiss AC. Management of diabetic trigger finger. J Hand Surg Am. 2018;44(2):1-4.

17. Lindsay JR, Kennedy L, Atkinson AB, Bell PM, Carson DJ, McCance DR, et al. Reduced prevalence of limited joint mobility in type 1 diabetes in a UK clinic population over a 20 -year period. Diabetes Care. 2005;28(3):658-61.

18. Dardas AZ, VandenBerg J, Shen T, Gelberman RH, Calfee RP. Long-term effectiveness of repeat corticosteroid injections for trigger finger. J Hand Surg. 2017;42(4):227-35.

\section{Como citar:}

Silva RE, Ribeiro SL, Souza BM, Souza CC, Faria RP, Faria RP. Comprometimento de mãos e punhos no diabetes tipo 2 - relato de caso. Rev Med UFC. 2020 out-dez;60(4):57-60. 